\title{
La aplicación del sufragio universal en Córdoba: las elecciones municipales de mayo de 1891
}

\section{ANTONIO BARRAGÁN MORIANA}

\section{INTRODUCCION}

Tras la aprobación de la ley de 26 de junio de 1.890 , la ley del sufragio universal, por un gobierno liberal que preside P.M. Sagasta, esta va a tener ocasión de ser aplicada por vez primera en las elecciones generales que se celebran en $1^{\circ}$ de febrero de 1.891. Evidentemente, la aprobación del sufragio universal había levantado una enorme polémica, tanto en los medios de comunicación, como en el Parlamento y ello por la extrema radicalidad de las posiciones de los diferentes partidos políticos, como por el hecho de que liberales y republicanos se disputen su paternidad. La prensa cordobesa del momento (.El Adalid", órgano de los reformistas de Romero Robledo, «La Lealtad• del conservadurismo canovista, "La Unión* del partido liberal-dinástico que en Córdoba reflejan las posiciones políticas del Conde de Cárdenas, del de Torres Cabrera y del duque de Hornachuelos respectivamente), se hace eco de esta polémica en torno al sufragio con similar intensidad a la que expresa la prensa madrileña y con intervención de los dirigentes políticos mas importantes de la provincia (Isasa, Conde y Luque, Garijo, Barroso, Belmonte Cárdenas, etc.); lógicamente, junto con otras cuestiones, unas de carácter general, otras de planteamientos mas localizados, tales como la permanencia de las prácticas caciquiles, la intervención de la autoridad gubernativa en el gobierno de los ayuntamientos, la segmentación de los partidos dinásticos y de la oposición republicana, la discusión en torno a la aprobación del presupuesto, etc., el tema del sufragio universal es uno de los considerados .estrella. en la campaña y su tratamiento se plantea en una banda que va desde la reivindicación de su paternidad por parte de los liberales ${ }^{1}$, que lo incluyen como una de las grandes aportaciones políticas del gobierno Sagasta (ley de jurados, Código Civil, ley de asociaciones, etc.), hasta las enormes reticencias de los conservadores o los "reformistas", pasando por la defensa a ultranza del mismo que efectúan los diversos grupos republi-

(1) .L'a Unión. 10-V-1.991. •Audaces fortuna iuvat.

DOI: http://dx.doi.org/10.25267/Trocadero.1993.15.09 
canos que consideran que es sólo gracias a su presión social, a su indiscutible alineamiento al lado de todo tipo de conquistas democráticas el que haya podido ser incorporado al ordenamiento jurídico/electoral ${ }^{2}$.

\section{LA COYUNTURA HISTORICA 1.890/91 EN LA PROVINCIA}

El año 1.891 viene significándose en la provincia de Córdoba, como en algunas otras andaluzas, por una notoria alza de la conflictividad social campesina y gremial; es evidente que tal conflictividad no sólo es imputable, como señala Díaz del $\mathrm{Moral}^{3}$, al eco que en el seno del movimiento obrero adquieren los acuerdos del Congreso de Paris de $1.889^{4}$, sino que, desde nuestro punto de vista, es necesario tener en cuenta una serie de circunstancias locales que suponen indudables estímulos en la movilización de las capas populares, siendo las mas visibles la enorme crisis de trabajo, consecuencia de la sequía y de la mala cosecha habida en el invierno de 1.890 , que reduce la oferta de empleo y provoca que durante todo el año se sucedan las peticiones de alojamientos" entre los labradores o de inversiones en obras públicas, ante la impotencia del ayuntamiento de Córdoba para atenderlas. A esto se añade la expansión de la filoxera en amplias zonas de la provincia, cuyos primeros brotes se habían detectado en 1.888 teniendo lugar la declaración oficial de provincia contagiada en abril de 1.890; según los trabajos de M. Lomas, en la provincia de Córdoba la plaga se deja sentir fundamentalmente en el entorno de la comarca montillana y en el entorno de la capital que, en adelante, y al menos hasta los años del conflicto europeo supondría un importante nivel de destrucción del cultivo, estando menos extendida al norte del Guadalquivir, lo que evidentemente supuso la ruina de muchos pequeños propietarios. Las movilizciones subsiguientes a este estado de crisis van a provocar que, como ocurre en el resto de la región, uno de los grandes problemas a solucionar por las organizaciones obreras sea el buscar un nivel de articulación suficientemente eficaz desde el punto de vista reivindicativo y que aumente su nivel de presencia entre los trabajadores del campo y el artesanado.

(2) Parn una polémica en torno al sufragio universal en la prensa cordobesa vid. BARRAGAN MORIANA, A. -Caciquismo y sufragio universal: Las elecciones generales de 1.891 en Córdoba., comunicación presentada al II Congreso de Historia de Andalucía. Córdoba 1.991

(3) DIAZ DEL MORAL, J. -Historia de las agitaciones campesinas andaluzas. Madrid 1.977, pags. 138 y ss.

(4) Vid. especialmente G.D.H. COLE, .Historia del pensamiento socialista, vol IV. .La Segunda Internacional. Méjico 1.960 y DROZ, J. Historia General del Socialismo., vol II. Barcelona 1.979

(5) LOMA RUBIO, M. "La llegada de la filoxera al viñedo cordobés, rev. "Axerquía", n 4. Córdoba 1.977 


\section{COMPOSICION SOCIOPROFESIONAL DE CORDOBA.CENSO DE 1891}

$\begin{array}{cccccccccccc}\text { DISTRTOO } & \text { ELECTORES } & \mathbf{1} & \mathbf{2} & \mathbf{3} & \mathbf{4} & \mathbf{5} & \mathbf{6} & \mathbf{7} & \mathbf{8} & \mathbf{9} & \mathbf{1 0} \\ \mathbf{1}^{\mathbf{2}} & 941 & 30.2 & 17 & 20.8 & 4.1 & 2.8 & 5.7 & 6.4 & 3.7 & 6 & 3.7 \\ 2^{2} & 955 & 76.7 & 4.4 & 3 & 1.8 & 2.6 & 0.6 & 2 & 0.4 & 0.2 & 1 \\ 3^{9} & 1423 & 26.6 & 10.4 & 20.6 & 4 & 7.8 & 10 & 5.7 & 3 & 6.9 & 4.8 \\ 4^{9} & 1467 & 39.1 & 14 & 14.6 & 7 & 5.1 & 7.4 & 5.1 & 1.5 & 2.6 & 2.5 \\ 5^{9} & 1473 & 41.2 & 15.9 & 10.4 & 5.6 & 6.7 & 5.9 & 3.6 & 5.3 & 2.2 & 0.5 \\ 6^{9} & 1480 & 45 & 17.9 & 12.6 & 6.8 & 6.5 & 6 & 3.1 & 5.3 & 1.7 & 3.2 \\ 7^{9} & 1516 & 74.6 & 8 & 3.2 & 4.8 & 2.2 & 1.5 & 0.9 & 1.7 & 0.6 & 0.5 \\ 8^{2} & 1594 & 76.9 & 7.4 & 3.4 & 3.4 & 1.3 & 1.5 & 0.4 & 1.5 & 0.6 & 0.9\end{array}$

Fuente: Censo electoral de Córdoba 1.891 (rectificado para las elecciones municipales de mayo). B.M.C.

En Córdoba, en plena campaña electoral el día 1 dé mayo se concentran unos 3.000 obreros que por primera vez pretenden desarrollar los acuerdos del congreso de París en un clima de importante conflictividad campesina y gremial'; de igual manera, no deja de tener clara influencia en la movilización popular la reactivación política republicana que, a pesar del mantenido fraccionalismo, da muestras de una nueva etapa en la que la reorganización será el vehículo que canalice políticamente las posibilidades del recién implantado sufragio universal. $Y$ en efecto, en esta coyuntura son numerosos los círculos, casinos o centros republicanos que se fundan (Rute, Bujalance Montoro y Palma del Río) o revitalizan (Villafranca, Baena y Aguilar). De esta reorganización de las fuerzas republicanas, así como probablemente de cierta dinamización lograda en algún distrito como consecuencia de la implantación del sufragio universal, es un claro ejemplo el éxito electoral obtenido el $1^{\circ}$ de febrero de 1.891 por la candidatura federal que representa J.Palma que obtiene el escaño en el distrito de Montilla frente a la oposición del reformista. Conde de Cárdenas, o el amplio apoyo de los federales A. Torres y Conde Salazar y el posibilista Villalba Burgos en la circunscripción de la capital. Pese a ello, no queremos dar la imagen de un republicanismo políticamente fuerte, capaz de convertirse en alternativa estable, siquiera a nivel municipal, a los partidos del turno, ni de una legislación que manifestase su operatividad sobre el cuerpo electoral. Todo lo contrario, el republicanismo provincial sigue afectado por un problema endémico que no es otro que el divisionismo, el enfrentamiento fraccional; en la provincia de Córdoba existen, aun a nivel de cuadros políticos, el núcleo del 'republicanismo histórico* o posibilista que en esta coyuntura dirigen E. Carreño, M. Zaragoza y M. Villalba Burgos, el grupo de los federales de Pi y Margall cuyos principales dirigentes son Amador Viñas y Angel Torres y que cuenta con importantes simpatías en

(6) Vid. nuestra refrencia nota $n^{2} 2$ y Diaz del Moral, $\cdot$ Historia de las agitaciones....., ob. cit. cap. 6 
comarcas o sectores influenciados por la propaganda anarquista, así como los republicanos progresistas de Ruiz Zorrilla, bastante numerosos, que dirigen Agustín Gallego Chaparro y Menacho del Castillo y, finalmente, después de su aparición en junio de 1.891 tendrán igualmente su grupo en Córdoba los republicanos "centralistas" de Nicolás Salmerón dirigidos por Eduardo Romero; de este confuso panorama, destacar sus frecuentes disputas, así como la reducción de gran parte de sus actividades a la celebración de algunas efemérides republicanas o progresistas (batalla de Alcoléa, los levantamientos republicanos de junio de 1.869, el 11 de feb. establecimiento de la I República, etc.).

\section{LA CAMPAÑA ELECTORAL}

Sin duda el tema central de la campaña electoral que no sólo determina las posiciones de los partidos del turno en la misma, sino que influye decisivamente en la inestabilidad del ayuntamiento de Córdoba hasta pasadas las elecciones, no es otro que la suspensión gubernativa del alcalde de Córdoba, el liberal Pedro Rey Gorrindo, junto a un grupo de concejales que son acusados de fraudes en la instrucción de impuesto de consumos y de malversación de fondos en una operación que tiene todo el talante de ser la típica sintervención caciquil• del gobernador civil Antonio Castañón Faes para preparar el terreno electoral a los conservadores; en sustitución de Rey Gorrindo es nombrado de R.O. Tejón y Marín que se mantendrá al frente de la alcaldía hasta 1.893.

La suspensión de los concejales liberales es el toque de campana que sitúa a los partidos monárquicos en condiciones de iniciar el enfrentamiento electoral y, en efecto, el comité provincial del partido liberal fusionista por voz de su máximo dirigente, el duque de Hornachuelos, y a través de su órgano de prensa protesta en un polémico y agresivo art ${ }^{2}$, "A la guerra con la guerra ${ }^{7}$, contra esta decisión gubernativa, a la vez que en las sesiones plenarias del ayuntamiento se desarrollan una serie de incidentes, y en las que los reformistas del Conde de Cárdenas, los liberales de A. González Aguilar y el mismo alcalde cesado obstruyen la labor del nuevo gobierno municipal que conduce, en principio, a levantar las sesiones, después a que estas se celebren exclusivamente con la presencia del alcalde interino y del secretario ${ }^{8}$; al no producirse el procesamiento de los concejales suspendidos y, en atención al art $^{9} .36$ de la ley electoral, estos son readmitidos en sus respectivas concejalías, aunque Tejón y Marín con el apoyo del Gobierno Civil no renuncia a su

(7) .La Provincia. 26-III-1.891

(8) .Elecciones municipales. Córdoba 1.891. Archivo Municipal. Legajo 22.3. Tabla 66 y 68 
cargo ${ }^{9}$ Su labor al frente de la administración municipal tiene un claro sesgo partidista y electoral como lo demuestra el nombramiento inmediato de alcaldes de barrio, así como la frecuentes reuniones *con fines electorales. en los locales del ayuntamiento de los círculos conservadores, o su control de la maquinaría burocrática electoral ( nombramiento de mesas electorales, de interventores, intervención ante la junta electoral, etc:), lo que no tardará en ser denunciado ante la opinión pública ${ }^{10}$.

Desde otro punto de vista, la campaña electoral de los liberales se centra en la inoperancia de la gestión conservadora, que ni siquiera aprovecha la inverosímil estancia. del Sr. Santos Isasa al frente del ministerio de Fomento para hacerse cargo de los importantes problemas de la ciudad de Córdoba, o en el grave enfrentamiento entre los sectores canovista y reformista; representados en la ciudad por el conde de Torres Cabrera y el conde de Cárdenas que dificultan la fluidez en las relaciones entre los grupos monárquicos y la solución de los problemas del ayuntamiento $^{11}$. Finalmente, ante la beligerancia del gobernador civil en el funcionamiento de determinadas instituciones de la ciudad (Ayuntamiento, Sociedad Económica de Amigos del País) el grupo liberal, a través de A. Barroso, presenta una querella contra él ante el Tribunal Supremo por manifiesto abuso de poder ${ }^{12}$. No obstante todo lo cual, y como muestra de aceptación del turnismo, los liberales hacen pública una nota en la que :....... en atención a tener buen número de concejales adictos en la parte del ayuntamiento suspendida que ha de funcionar dentro del próximo bienio...sólo presenta el partido liberal dinástico candidatos en 3 distritos de los 8 y en los 5 restantes apoyará opciones monárquicas liberales para el triunfo del candidato de oposición:.....13.

Por su parte, la prensa conservadora justifica la sustitución al frente de la alcaldía para lo que, en su opinión, sólo se ha aplicado la legislación vigente, señalando las dificultades de gobierno en la coyuntura y los enormes méritos del sr. Tejón y Marín en la dirección del consistorio local ${ }^{14}$. La posición política de los conservadores en el gobierno del ayuntamiento de la ciudad trasciende a la prensa regional y de Madrid y así en -El Imparcial, se insiste en el importante apoyo del pueblo de Córdoba al

(9) Elecciones municipales. Córdoba 1.891, vid. legajo referenciado nota anterior

(10) LLa Provincia. $1^{2}$-VI-1.891

(11) Las condiciones de unificación de ambos grupos conservadores resultaban especialmente costosas para los .reformistas. de Romero Robledo dirigidos en Córdoba por el Conde de Cárdenas, ya que se exigía su disolución inmediata, la desautorización política de Romero Robledo y paso de los cuadros al canovismo.

(12) -La Provincia. 22-IV-1.891

(13) LLa Provincia. 25-IV-1.891

(14) La Lealtad. 23-IV-1.891 
alcalde interino, así como en sus continuos éxitos (temas de los impuestos municipales, del cuartel de infantería, del paro obrero, etc.) para, finalmente, abordar las dificultades de los fusionistas en la elaboración de su candidatura municipal, en la medida en que a..... sólo se presentan barrosistas y lopezdominguistas, habiendo quedado desbancados los armijistas y los garijistas.... ${ }^{15} \mathrm{y}$ manifestando, como ya habían hecho en las elecciones generales de $1^{\circ}$ de febrero de 1.891 , sus enormes reticencias ante el sufragio universal, ‘..... molestísimo en su aplicación y que provoca el caos en la multitud inconsciente....ya que además las corporaciones nacidas del sufragio están por su naturaleza y por la encrucijada de las leyes tan a merced del gobierno como lo estaban las anteriores a su establecimiento y el cuerpo electoral tan perfectamente dispuesto como estaba antes a cambiar tan pronto sople el viento de otro lado......16.

Desde otro punto de vista político, los dirigentes republicanos, se mantienen al margen de esta disputa caciquil y, a la vista del éxito obtenido en las elecciones generales de febrero, deciden presentar una candidatura conjunta. Su campaña se centra tanto en la realización de una serie de actos públicos en aquellos barrios de fuerte componente popular (San Andrés, San Lorenzo, Santa Marina, etc.) esforzándose en demostrar la posibilidad de otra forma de hacer política de manera mas participativa ${ }^{17} y$ en denunciar determinados aspectos de la administración municipal y central; el acto central de su campaña del que se hizo eco la prensa monárquica fue la celebración el día 8 de mayo de un gran mitín en el teatro principal en el que intervienen tanto los dirigentes del republicanismo local (Angel Torres, Fdco. Barranco, Emilio Carreño, Menacho del Castillo), los candidatos por algunos distritos (Luis Valenzuela, M. Zaragoza, Barrionuevo) que insisten en el tema de los impuestos municipales y en la crisis de trabajo y, finalmente, el Dr. Esquerdo, hombre fuerte del "zorrillismo", que cierra el acto planteando la equivalencia entre democracia y república ${ }^{18}$.

La intervención de la administración gubernativa, como señalábamos mas arriba, es inmediata y va desde el control final del censo, que queda definitivamente fijado en 10.849 electores de los que sólo 918 son elegibles para cargos concejiles y que suponen un aumento considerable con relación al censo de 1.890 , aunque las numerosas altas y bajas en el

(15) Citado por $\cdot$ El Adalid., 22-IV-1.891

(16) Vid. referencia nota anterior.

(17) Los resultdos de las elecciones generales de 1.891, en lo que a la ciudada de Córdoba se refiere, ya habían proporcionado un importante éxito para la candidatura republicana en barrios de fuerte composición social popular. Vid. nuestro trabajo referenciado en nota $n^{\circledR} 2$.

(18) El acto tuvo una importante acogida en la prensa local, incluso en la monárquica, debido básicamente al enorme prestigio político del que disfrutaba el Dr. Esquerdo, como asímismo es reconocido. 
mismo dan idea de un importante grado de manipulación al que ha sido sometido $^{19}$, la proclamación de las candidaturas, hasta la aprobación definitiva de las mesas electorales que, finalmente, se constituyen tomando parte los concejales suspensos, y de las listas de interventores ${ }^{20}$.

\section{LOS RESULTADOS ELECTORALES}

Aunque la prensa del día 12 reconoce que durante las elecciones se han pagado los votos a 5 y 7 pesetas y que se han producido determinados incidentes, consecuencia del mucho vino que las candidaturas han repartido entre los electores, lo cierto es que su frecuencia es mucho menor comparativamente, tanto a juzgar por sus testimonios, como por lo escaso de las impugnaciones presentadas posteriormente en el escrutinio y que afectan mas a la confección de las candidaturas que a la propia realización de las elecciones.

\section{RESULTADOS ELECTORALES. ELECCIONES MUNICIPALES (mayo 1891) CENSO ELECTORAL DE CORDOBA}

DISTRITO $1^{2}$

Elige 2 - Electores 985 - Votantes 590

$\begin{array}{lrrc}\text { Secciones } & 1^{3} & 2^{2} & \text { Total } \\ \text { R.Tejón y Marin } & 142 & 143 & 285 \\ \text { Antonio Carrasco } & 114 & 71 & 185 \\ \text { Julio Valdelomar } & 49 & 66 & 115\end{array}$

DISTRITO $2^{\circ}$

Elige 1 - Electores 952 - Votantes 469

$\begin{array}{lrrc}\text { Secciones } & 1^{2} & 2^{*} & \text { Total } \\ \text { Mariano Zaragoza } & 142 & 185 & 327 \\ \text { J.Rebollo Fernández } & 105 & 34 & 139\end{array}$

DISTRITO $3^{\circ}$

$\begin{array}{lrccc}\text { Secciones } & \mathbf{1}^{\mathbf{z}} & 2^{\mathbf{z}} & 3^{\mathbf{z}} & \text { Total } \\ \text { Fco.Blanco Rodriguez } & 103 & 78 & 112 & 293 \\ \text { J.M.Molina Fernández } & 80 & 91 & 112 & 283 \\ \text { L.Gutierrez Rios } & 102 & 76 & 94 & 272 \\ \text { Francisco Barbudo } & 69 & 63 & 95 & 227 \\ \text { C.Casas Santaella } & 70 & 82 & 68 & 220 \\ \text { Antonio Junguito } & 69 & 63 & 66 & 198\end{array}$
(19) -Elecciones municipales. Córdoba 1.891. Censo electoral. Archivo municipal. Legajo
22.3. Tabla 66 y 68

(20) -Diario de Córdoba., 26-1V-1.891 


\section{DISTRITO $4^{\circ}$}

Elige 2 - Electores 1.495 - Votantes 675

$\begin{array}{lrrrr}\text { Secciones } & 1^{2} & 2^{2} & 3^{2} & \text { Total } \\ \text { R. Moya Aragón } & 111 & 129 & 93 & 333 \\ \text { M. Trigos F.Cañete } & 74 & 111 & 137 & 322\end{array}$

DISTRITO $5^{\circ}$

Elige 3 - Electores 1.496 - Votantes 830

$\begin{array}{lrrrr}\text { Secciones } & 1 & 2^{2} & 3^{3} & \text { Total } \\ \text { J. de Oliva González } & 208 & 170 & 100 & 478 \\ \text { Fco. Cruz Córdoba } & 198 & 168 & 97 & 463 \\ \text { A. Muñoz Collado } & 83 & 121 & 151 & 355 \\ \text { G. Larriba Ramos } & 76 & 116 & 152 & 344\end{array}$

DISTRITO $6^{\circ}$

Elige 3 - Electores 1.492 - Votantes 799

$\begin{array}{lrrrc}\text { Secciones } & \mathbf{1}^{\mathbf{3}} & 2^{\mathbf{2}} & 3^{\mathbf{a}} & \text { Total } \\ \text { Rafael Barrionuevo } & 157 & 157 & 142 & 456 \\ \text { Luis Valenzuela } & 157 & 150 & 139 & 446 \\ \text { E. Fuentes Breña } & 90 & 88 & 109 & 287 \\ \text { R. Roldán Arana } & 84 & 94 & 93 & 271\end{array}$

DISTRITO $7^{\circ}$

Elige 3 - Electores 1.491 - Votantes 637

$\begin{array}{lrrrr}\text { Secciones } & 1^{\mathbf{a}} & 2^{\mathbf{2}} & 3^{\mathbf{2}} & \text { Total } \\ \text { V. Rivera Moreno } & 146 & 143 & 153 & \mathbf{4 4 2} \\ \text { José Ramos Blasco } & 100 & 129 & 148 & 377 \\ \text { J.A.Rodríguez Jiménez } & 67 & 60 & 45 & 172 \\ \text { Antonio Bajo Sánchez } & 65 & 59 & 45 & 169 \\ \text { Idelfonso Iaguna } & 61 & 25 & 7 & 93\end{array}$

DISTRITO $8^{\circ}$

Elige 2 - Electores 1.475 - Votantes 636

$\begin{array}{lrrrc}\text { Secciones } & 1^{\mathbf{a}} & 2^{\mathbf{z}} & 3^{\mathbf{2}} & \text { Total } \\ \text { Manuel Morales Reina } & 139 & 95 & 102 & 335 \\ \text { Antonio Ariza Victor } & 32 & 57 & 58 & 147 \\ \text { Jose Rdriguez.Jiménez } & 41 & 66 & 39 & 146\end{array}$

Fuente: Archivo Municipal de Córdoba. Legajo 11.04.Elecciones municipales. Est.23.3. Caja 60

Consiguientemente son elegidos los siguientes candidatos: 10 republicanos (A. Carrasco en el $1^{\circ}$, M. Zaragoza en el $2^{\circ}$, M. Trigos en el $4^{\circ}$, J. de Oliva y Fco. Cruz Córdoba en el $5^{\circ}$, R. Barrionuevo y Luis Valenzuela en el $6^{\circ}$, V. Rivera y J. Ramos en el $7^{\circ}$ y M. Morales en el $8^{\circ}$ ), 7 conservadores (Tejón y Marín en el $1^{\circ}$, Fco. Blanco y Gutierrez de los Rios en el $3^{\circ}$, R. Moya en el $4^{\circ}$, Muñoz Collado en el $5^{\circ}$, Fernandez Breña en el $6^{\circ}$ y J.A. Rodriguez en el $7^{\circ}$ ) y 2 reformistas (J.M. Molina en el $3^{\circ}$ y A. Ariza 
Victor en el $8^{\circ}$ ), lo que supone un triunfo sin precedentes de las fuerzas republicanas en el ayuntamiento de Córdoba.

La abstención correspondiente al conjunto de la ciudad es del $51 \%$ y por distritos la siguiente:

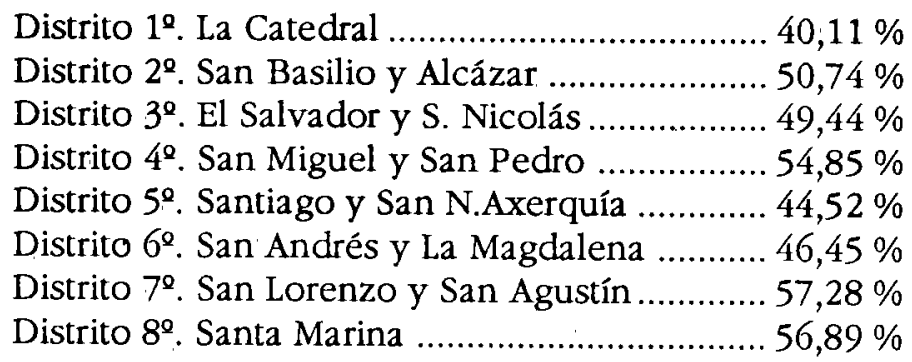

El éxito republicano que se produce tanto en los barrios de fuerte componente sociológico de jornaleros (San Basilio y Alcázar Viejo, San Lorenzo y Santa Marina), como sobre todo en los de presencia artesanal (San Pedro, Santiago y San Andrés y La Magdalena) es bien recibido incluso por la oposición liberal que aún vive la resaca del reciente enfrentamiento por la alcaldía, aunque no puedan ocultar su decepción con respecto a sus propios candidatos $^{21}$; por su parte la prensa conservadora, a través de su órgano de expresión, "La Lealtad., pretende camuflar su derrota ante la candidatura republicana argumentando que aún poseen mayoría en el consistorio, lo que garantiza la continuidad de Tejón y Marín al frente del mismo.

El escrutinio realizado el día 12 de mayo presenta una serie de reclamaciones sobre distintos colegios, personas y capacidades ${ }^{22}$, entre otras, las siguientes:

a) reclamación del candidato reformista y director del diario $\mathrm{El}$ Adalidu, J. Valdelomar, contra la elección del Sr. Tejón y Marín fundada en que este es ingeniero militar supernumerario.

b) protesta igualmente del mismo por las coacciones del visitador de consumos sobre los empleados del ramo.

c) en el segundo distrito D. F. Gamboa Matos presenta una reclamación contra los resultados al tener constancia de serias infracciones en el censo.

d) en el distrito cuarto, se presenta una protesta por parte del propio presidente de la mesa $3^{\mathbf{a}}$ contra su nombramiento porque la legislación vigente le prohibe desempeñar tareas electorales.

e) en el sexto, finalmente, se presenta una protesta contra la elección del Sr. Fuentes Breña, concejal electo que no aparece en el censo ni como elector, ni como elegible.

(21) .La Provincia., 12-V-1.891

(22) "Diario de Córdoba., 14-V-1.891. Elecciones municipales*. Córdoba 1.891. Escrutinio. Archivo municipal. Legajo citado nota 19 
En los distritos $3^{\circ}, 5^{\circ}, 6^{\circ}, 7^{\circ}$ y $8^{\circ}$ no se presenta ninguna reclamación, aunque todas las habidas se resuelven negativamente para sus peticionarios ${ }^{23}$.

La toma de posesión del nuevo ayuntamiento no se produce hasta el $1^{9}$ de julio y precisamente en este acto los republicanos por voz de V. Rivera y L. Valenzuela protestan de la constitución del nuevo consistorio por considerarlo ilegal, en la medida en que no se atendieron ninguna de las justificadas protestas que formularon en el escrutinio, dándose, a continuación, lectura al nombramiento de R.O. de alcalde/presidente del ayuntamiento para el bienio 1.891/93 nuevamente en la persona de J. Tejón y Marín y procediéndose a la elección de los tenientes de alcaldes que recae en los conservadores L. Gurierrez de los Cobos, R. González Ripoll y R. Moya Aragón, absteniéndose los concejales republicanos que, no obstante, aceptan su entrada en algunas comisiones.

\section{CONCLUSIONES}

La implantación del sufragio universal y su aplicación a los diferentes comicios, generales y municipales supuso, en principio, una cierta reactivación política en el caso de la provincia y de la ciudad de Córdo$\mathrm{ba}$, tal como demuestran los resultados electorales de $1^{2}$ de febrero y de 10 de mayo. Es claro que la notable ampliación del cuerpo electoral aumentó las expectativas de desarrollo de la oposición antimonárquica. Sin embargo, a pesar de la gravedad de las disidencias en el seno de los grupos fusionista y conservador, auténtica expresión de intereses caciquiles, el republicanismo cordobés no conseguirá articularse como alternativa eficaz, desde el punto de vista de la administración municipal y a ello no era ajeno el que, al tener bloqueada su capacidad política en el ayuntamiento cordobés, muy pronto resurgirían los enfrentamientos entre los distintos grupos republicanos y, consiguientemente, el alejamiento del voto popular de las opciones antidinásticas.

Si a ello unimos la cada vez mas fuerte presencia de la propaganda anarquista entre las clases trabajadoras hacia finales dei XIX, podremos colegir que, finalmente, la implantación del sufragio universal terminaría convirtiéndose en una auténtica "coartada legal• para la legislación electoral, que, en absoluto, supondría no ya la eliminación de los tradicionales vicios caciquiles, sino que daba carta de naturaleza a una sistema pretendidamente democrático y que en realidad era sólo un instrumento mediante el que las élites políticas y económicas, si bien haciendo mas complejas sus redes de clientelismo, lograron el control de la sociedad cordobesa.

(23) Vid. referencia nota anterior 